\title{
Zooplankton community distribution in shallow reservoirs during winter: Influence of environmental factors on Cyclops vicinus (Copepoda: Cyclopoida)
}

\author{
Jong-Yun Choi ${ }^{1}$, Kwang-Seuk Jeong ${ }^{1,2}$ and Gea-Jae Joo ${ }^{1, *}$ \\ ${ }^{1}$ Department of Biological Sciences, Pusan National University, Busan 609-735, Korea \\ ${ }^{2}$ Institute of Environmental Science \& Technology, Pusan National University, Busan 609-735, Korea
}

\begin{abstract}
We estimated the influence of environmental factors on zooplankton communities at 25 reservoirs during winter (December 2010 to January 2011). Among zooplankton groups, Cyclops vicinus is more dominant during winter, and this is positively related to withered vegetation area and dissolved oxygen level. Therefore, the presence of withered vegetation might be considered as an important factor to determine C. vicinus distribution during winter. We considered that withered vegetation might be utilized as a habitat for $C$. vicinus, as well as provide an attachment substrate for periphytic algae. Abundance of periphytic algae can lead to high concentration of dissolved oxygen. Although copepods prefer high water temperatures for increasing their population growth, if Cyclops can overcome low temperature stress that leads to disruption of population, their population growth initiation in the next growing season (i.e. next spring) is possibly propelled by the winter population.
\end{abstract}

Key words: Cyclops vicinus, environmental parameters, winter, withered aquatic plant areas

\section{INTRODUCTION}

Zooplankton distribution is strongly influenced by water body environmental variables, such as abiotic factors (e.g., water temperature, salinity, stratification, and advection), biotic factors (e.g., food limitation, predation, and competition), or a combination of both (Roff et al. 1988, Escribano and Hidalgo 2000, Beyst et al. 2001). Therefore, recognition of environmental variables in the distribution of zooplankton has been central to limnological research. In temperate regions, environmental factors in water bodies change dramatically according to the season, which determines the seasonal ontogeny and population growth of zooplankton (Marneffe et al. 1996).

Among diverse environmental factors, water tempera- ture is clearly altered by seasonality, and controls metabolic rates and circadian rhythms, such as mating and dormancy (Hirche 1987, Robinson et al. 1983). Low water temperatures decrease the metabolism of zooplankton, which reduces their life cycle and feeding. The aforementioned circumstances affect their predators (mainly fish) as well (Brandt 1993), and hence, winter is believed to be a unique period during which zooplankton are not interrupted by predators. Therefore, we hypothesize that zooplankton communities in winter are affected by different environmental variables when compared with other seasons (spring, summer, and autumn). In particular, withered vegetation does not reduce phytoplankton biomass http://dx.doi.org/10.5141/ecoenv.2014.012

(1) \$ This is an Open Access article distributed under the terms of the Creative Commons Attribution Non-Commercial Licens (http://creativecommons.org/licenses/by-nc/3.0/) which permits unrestricted non-commercial use, distribution, and reproduction in any medium, provided the original work is properly cited.
Received 15 March 2014, Accepted 15 April 2014

*Corresponding Author

E-mail: gjjoo@pusan.ac.kr

Tel: +82-51-510-2258 

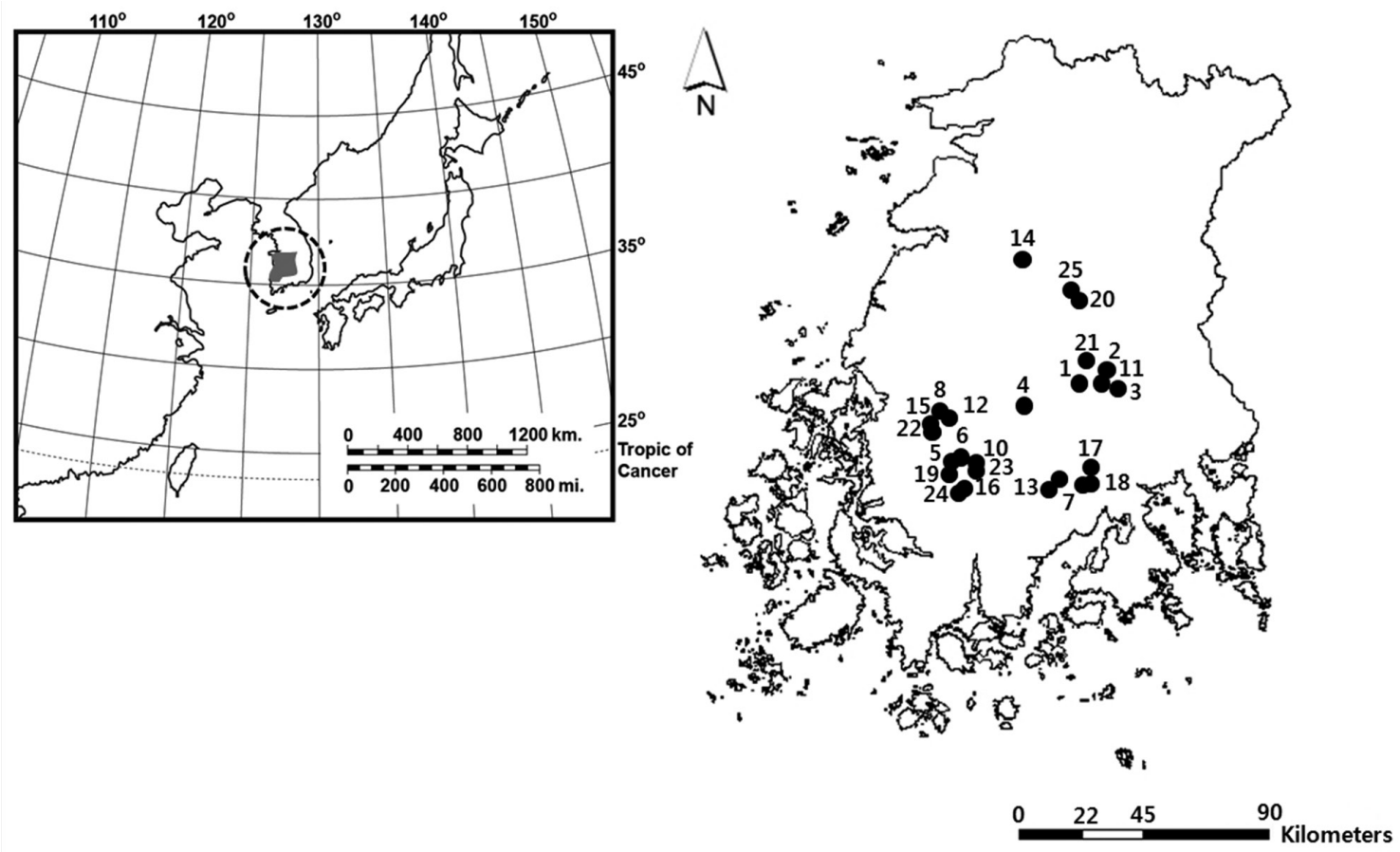

Fig. 1. Map showing the study sites in the southwestern region of South Korea. The left map shows the Korean Peninsula, and the gray part (enclosed in the dotted circle) is the Yeongsan River basin. The right map is the river basin with the locations of the study sites (black dots; numbers indicate the serial number of study sites corresponding to Table 1).

through shading effects (Sand-Jensen and Søndergaard 1981) and allelopathy (van Donk and van de Bund 2002), and should thus support a large abundance of not only food sources, but also zooplankton. Unfortunately, distribution patterns of zooplankton related to environmental variables during winter have been insufficiently studied.

The primary objective of our study was to investigate the distribution pattern of zooplankton during winter. We investigated the following: (1) the influence of diverse environmental variables on zooplankton distribution, and (2) the contribution of withered vegetation to support a large abundance of zooplankton.

\section{MATERIALS AND METHODS}

South Korea is located in East Asia, and possesses a temperate climate. Four distinct seasons lead to a dynamic succession of the biological community in Korean freshwater ecosystems. In particular, this country experiences an average temperature of $-0.8^{\circ} \mathrm{C}$ during winter (from December to January). The reservoirs monitored in this study are located in southwestern Korea, within the central and lower reaches of the Yeongsan River (Fig. 1). We investigated environmental parameters (reservoir area, withered vegetation area, water temperature, dissolved oxygen, and chlorophyll $a$ ) and zooplankton communities in 25 reservoirs during winter (December 2010 to January 2011). We established three sampling points in littoral zone of each reservoir. The sampling points were randomly selected based on virtual grids constructed over maps of the reservoirs. We used a YSI 58 dissolved oxygen (DO) meter (YSI Inc., Yellow Springs, OH, USA) to detect water temperature and DO (\% saturation). Chlorophyll $a$ concentration was measured using a spectrophotometer in accordance with Wetzel and Likens (2000). Reservoir area and withered aquatic plant area were measured using ESRI's ArcGIS ver. 9.3 (ESRI Inc., Redlands, CA, USA) and a digital map from National Geographic Information Institute (http://www.ngii.go.kr) with a scale of 1 to 25,000 .

For zooplankton collection, we collected $5 \mathrm{~L}$ water samples using a $10 \mathrm{~L}$ column sampler at each sampling point. The sampled water was filtered through a plankton net (32- $\mu \mathrm{m}$ mesh net), and the filtrate was preserved in formaldehyde (final concentration: 5\%). The zooplankton were identified and counted using an Axioskop microscope 40 (Carl Zeiss, Oberkohen, Germary) at ×200 magnification, based on the classification key published by Mizuno and Takahashi (1999). 
Canonical correspondence analysis (CCA) was used to identify the relationship between the zooplankton communities and environmental parameters by using Canoco ver. 4.5 (Ter Braak and Smilauer 1998).

\section{RESULTS}

The observed levels for environmental factors (reservoir area, withered vegetation area, water temperature, dissolved oxygen level, and chlorophyll $a$ level) at study sites are listed in Table 1. Even though some reservoirs showed exceptionally high or low relative values for these parameters, the coefficients of variation (CV) were less than $100 \%$. The average water temperature ranged from 1.1 to $5.4^{\circ} \mathrm{C}$, while DO (81\% to $144 \%$ ) and chlorophyll $a$ (1.7 to $12.5 \mu \mathrm{g} / \mathrm{L}$ ) showed wider ranges than that of the water temperature. The reservoir area and withered aquatic plant area showed the largest ranges of 4,861-443,166 ha and 0-20,189 ha, respectively.

Zooplankton were collected across all investigated

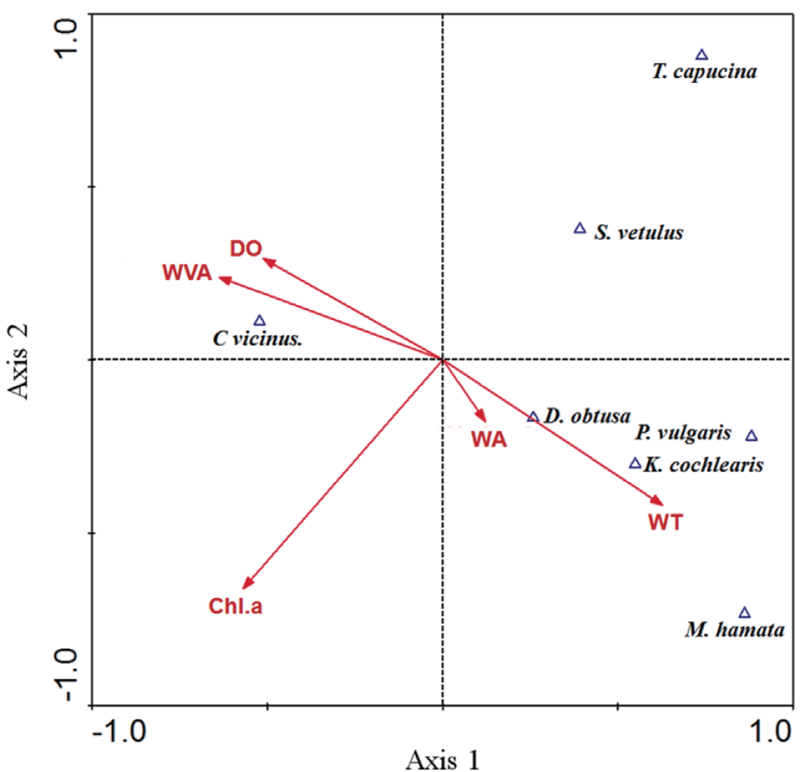

Fig. 2. Ordination of environmental parameters and zooplankton species $(\Delta)$ by canonical correspondence analysis (CCA). WA, wetland area $\left(\mathrm{m}^{2}\right)$; WVA, withered vegetation area $\left(\mathrm{m}^{2}\right) ; \mathrm{WT}$, water temperature $\left({ }^{\circ} \mathrm{C}\right) ; \mathrm{DO}$, dissolved oxygen (\%); Chl.a, chlorophyll a ( $\mu \mathrm{g} / \mathrm{L})$.

Table 1. Environmental parameters measured at study sites during winter. WVA, withered vegetation area; WT, water temperature; DO, dissolved oxygen; Chl.a, chlorophyll $a$

\begin{tabular}{|c|c|c|c|c|c|c|}
\hline Site number & Site name & Area $\left(\mathrm{m}^{2}\right)$ & WVA $\left(\mathrm{m}^{2}\right)$ & $\mathrm{WT}\left({ }^{\circ} \mathrm{C}\right)$ & DO (\%) & Chl.a $(\mu \mathrm{g} / \mathrm{L})$ \\
\hline 1 & Banghyeon & 4,945 & 2,142 & 1.1 & 122 & 1.3 \\
\hline 2 & Dugok & 7,373 & 891 & 3.6 & 113 & 2.4 \\
\hline 3 & Gagok & 11,171 & 2,417 & 2.4 & 141 & 5.3 \\
\hline 4 & Ganmoon & 103,056 & 10,428 & 1.4 & 137 & 7.4 \\
\hline 5 & Geumdan & 10,717 & 8,947 & 3.2 & 114 & 3.2 \\
\hline 6 & Geumgok & 5,251 & 1,024 & 4.7 & 128 & 1.4 \\
\hline 7 & Geumpung & 14,067 & 24 & 4.6 & 111 & 2.4 \\
\hline 8 & Hayetea & 26,166 & 2,457 & 5.2 & 144 & 3.3 \\
\hline 9 & Heukseok & 8,314 & - & 3.3 & 128 & 1.4 \\
\hline 10 & Hwadea & 5,703 & 3,417 & 2.8 & 112 & 5.2 \\
\hline 11 & Jangan & 32,127 & 3,457 & 2.1 & 117 & 8.3 \\
\hline 12 & Mewol & 5,999 & 5,999 & 2.1 & 111 & 5.5 \\
\hline 13 & Мeyo & 20,189 & 20,189 & 1.6 & 143 & 4.1 \\
\hline 14 & Meyori & 180,488 & - & 2.6 & 94 & 6.2 \\
\hline 15 & Mokdong & 11,850 & 6,737 & 1.6 & 118 & 2.3 \\
\hline 16 & Ohdong & 42,306 & - & 3.7 & 88 & 3.4 \\
\hline 17 & Okgye & 443,166 & 28 & 3.4 & 94 & 2.4 \\
\hline 18 & Omi & 7,063 & 4,045 & 2.5 & 115 & 3.3 \\
\hline 19 & Sinchon & 6,479 & 937 & 3.2 & 106 & 4.7 \\
\hline 20 & Sinwol & 83,978 & - & 2.4 & 83 & 0.6 \\
\hline 21 & Ssangyong1 & 57,381 & - & 5.4 & 89 & 2.5 \\
\hline 22 & Ssangyong2 & 208,162 & - & 4.2 & 81 & 2.6 \\
\hline 23 & Sunhwa & 5,035 & 234 & 3.9 & 111 & 4.5 \\
\hline 24 & Supmol & 25,909 & 5,065 & 3.2 & 116 & 8.4 \\
\hline 25 & Yangcheon & 4,861 & 2,147 & 2.9 & 118 & 1.2 \\
\hline
\end{tabular}


reservoirs, but no zooplankton was found in the sites 2 , 7, 9, and 17 (Table 2). Cyclops vicinus was predominant among the zooplankton groups, with densities of other zooplankton species (i.e., cladocerans and rotifers) being relatively low. The highest density of C. vicinus was found at site No. 13 (271 individual/L on average), followed by No. 5 (218 individual/L on average). The densities of other zooplankton did not differ between study sites.

The results of CCA showed the relationship between environmental factors and zooplankton species (Fig. 2). The eigenvalues for CCA axis 1 and axis 2 were 0.73 and 0.46 , respectively, and they accounted for $54.2 \%$ of the cumulative variance in the species data. The species-environment correlations for CCA axes 1 and 2 were high, and accounted for $68.2 \%$ of the variance in the species composition-environment relationship. Specifically, the withered vegetated area and DO had a strong effect on C. vicinus, Monostyla hamata, Keratella cochlearis, Polyarthra vulgaris, and Daphnia obtusa densities and compositions, which were associated with both the reservoir area and water temperature.

\section{DISCUSSION}

In this study, we found high densities of C. vicinus in shallow reservoirs during winter. Copepods are commonly abundant under high water temperature conditions from spring to autumn (Huq et al. 1984), and winter typically constitutes low densities. Low water temperature leads to decreased metabolic rates in copepods, and a decrease in their population growth. However, some studies have reported the presence and density pattern of copepods during winter (Hoffmeyer 1994, Dejen et al. 2004). Copepods present during winter are believed to be responsible for sustaining copepod abundance at certain levels in the following autumn seasons. Moreover, copepod abundance in winter can largely contribute to population growth in spring. Importantly, the increased number of copepods in spring can be utilized as food items for the growth of secondary consumers, such as juvenile fish and macroinvertebrates.

From results of the CCA analysis, we found that co-

Table 2. Zooplankton species density (individual/L) at study sites during winter

\begin{tabular}{|c|c|c|c|c|c|c|c|}
\hline Site number ${ }^{*}$ & C. vicinus & D.obtusa & S. vetulus & K. cochlearis & P. vulgaris & M. hamata & T. capucina \\
\hline 1 & $61.3 \pm 24.1$ & - & - & $17.5 \pm 11.5$ & $8.4 \pm 2.4$ & - & - \\
\hline 2 & - & - & - & - & - & - & - \\
\hline 3 & $26.3 \pm 14.2$ & $17.5 \pm 3.4$ & $15.0 \pm 5.4$ & - & - & - & - \\
\hline 4 & $17.5 \pm 3.4$ & - & - & - & - & - & - \\
\hline 5 & $218.8 \pm 47$ & - & - & - & - & - & - \\
\hline 6 & $8.8 \pm 2.7$ & - & - & $14.5 \pm 6.3$ & $1.2 \pm 2.8$ & $6.8 \pm 5.7$ & $9.1 \pm 2.5$ \\
\hline 7 & - & - & - & - & - & - & - \\
\hline 8 & $70.0 \pm 25$ & - & - & $7.5 \pm 2.7$ & $6.3 \pm 1.6$ & - & - \\
\hline 9 & - & - & - & - & - & - & - \\
\hline 10 & $70.0 \pm 24.7$ & $8.8 \pm 1.6$ & - & $16.3 \pm 12.7$ & - & $14.6 \pm 6.7$ & - \\
\hline 11 & $43.8 \pm 10.6$ & $6.3 \pm 1.9$ & $8.8 \pm 2.4$ & - & - & - & - \\
\hline 12 & - & - & - & - & - & $13.2 \pm 5.7$ & $4.7 \pm 3.5$ \\
\hline 13 & $271.3 \pm 12$ & $43.8 \pm 12.3$ & $17.5 \pm 8.4$ & - & - & - & - \\
\hline 14 & $140.0 \pm 37$ & - & $7.2 \pm 3.5$ & - & - & - & - \\
\hline 15 & $113.8 \pm 23$ & - & - & - & - & - & - \\
\hline 16 & $70.0 \pm 13.4$ & - & $5.0 \pm 2.7$ & - & - & $4.1 \pm 1.5$ & $7.9 \pm 3.7$ \\
\hline 17 & - & - & - & - & - & - & - \\
\hline 18 & $96.3 \pm 4.5$ & - & - & - & - & - & - \\
\hline 19 & $26.3 \pm 12.4$ & - & $13.4 \pm 14.7$ & $6.7 \pm 2.1$ & - & $11.5 \pm 6.3$ & - \\
\hline 20 & $183.8 \pm 19$ & $8.8 \pm 2.3$ & - & - & - & - & - \\
\hline 21 & $122.5 \pm 29$ & - & - & $6.3 \pm 3.4$ & $5.6 \pm 2.8$ & $5.7 \pm 6.4$ & - \\
\hline 22 & - & $12.5 \pm 2.7$ & $8.8 \pm 2.4$ & $17.5 \pm 7.3$ & $17.1 \pm 6.4$ & $1.8 \pm 0.6$ & - \\
\hline 23 & - & - & - & $8.8 \pm 5.4$ & $6.7 \pm 1.4$ & - & $13.7 \pm 6.7$ \\
\hline 24 & $183.8 \pm 12$ & $5.0 \pm 2.8$ & $5.0 \pm 1.7$ & - & - & - & - \\
\hline 25 & $26.3 \pm 12.4$ & $13.2 \pm 0.4$ & $8.8 \pm 2.7$ & - & - & - & - \\
\hline
\end{tabular}

"Site number corresponds to the serial number of study sites listed in Table 1. 
pepod density was related to withered vegetation area. Even though area of withered vegetation does not always be proportional to the occupied space by the vegetation, a strong positive relationship between $C$. vicinus and withered vegetation area was found $\left(r^{2}=0.76, P<0.01\right)$, implying that the height of withered vegetation had relatively constant influence. Strong association of C. vicinus with withered vegetation area in CCA result would be explained by the circumstance. Generally, aquatic vegetation is utilized as a refuge to avoid predators such as fish, and thus can help to increase the density of zooplankton, include copepods (Manatunge et al. 2000, KuczyńskaKippen and Nagengast 2006). Although the foraging activity of predators is reduced in low water temperatures (Jang et al. 2006, Carey et al. 2010, Theel and Dibble 2008), some predators can consume prey species under such conditions, and in such a case, withered vegetation can be utilized as a habitat for copepods. Therefore, the presence of withered vegetation might be considered an important factor in determining C. vicinus distribution during winter. Furthermore, macrophytes, through nutrient competition and allelopathy with phytoplankton (Van Donk and Van de Bund 2002), can decrease algal food for zooplankton, but withered vegetation may exert a limited effect on the phytoplankton. Although chlorophyll $a$ did not show a close relationship to copepod density in the present study, the possibility cannot be entirely excluded. This is one of reasons why withered vegetation could support a high density of copepods. The withered vegetation is not influenced by periphytic algae or phytoplankton; moreover, the leaves and stem surfaces are used as a habitat for periphytic algae. Based on this information, our results should indicate that the high concentrations of dissolved oxygen seen are due to the high amount of periphytic algae present.

Non-copepod zooplankton species were partly analyzed by environmental parameters in the CCA. The presence of Daphnia obtusa, Polyarthra vulgaris, Keratella cochlearis, and Monostyla hamata was related to both reservoir area and water temperature. However, the occurrence of other zooplankton species at the 25 study sites was relatively low (Table 2), indicating that the aforementioned relationship should be considered cautiously.

In the present study, we hypothesized two possibilities for copepod (i.e., C. vicinus) distribution under low water temperatures: (1) predator foraging is strongly dependent on water temperature (Byström et al. 2006), with copepods showing high densities, because the foraging activity of predators deceases under low water temperatures and (2) the resting eggs of copepods might exhibit hatch- ing selection based on lower water temperatures. Copepods are always exposed to predation under higher water temperatures (Turner 1984), and to avoid predators, their hatching mechanisms might show a strong possibility for adaptation to low water temperatures. We found abundant egg-shells of copepod resting eggs in several reservoirs during the study period (sites 2,12 , and 16) which allows us to suspect the possibility, even though we cannot assure the hatching timing of the resting eggs.

We expect that withered vegetation in water body supports tolerance of Cyclops population to unfavorable growth condition (i.e., low temperature in winter), leading to persistence of population size at a certain level. In this study, we observed very low abundance of Cyclops in the area where withered vegetation was absent. On the contrary, their abundance was larger as withered vegetation was abundant. Although copepods prefer high water temperatures for increasing their density and population growth, if Cyclops can overcome low temperature stress that leads to disruption of population, their population growth initiation in the next growing season (i.e., next spring) is possibly propelled by the winter population. Also, the tolerance to winter season may advantage $C y$ clops population to avoid extensive predation impact in summer. Typically their predators have increased foraging activity under high water temperature, and possible temperature tolerance coupled with withered vegetation may allow to avoid summer predation. This hypothetical advantage in compliance with mechanism of Cyclops persistence in withered vegetation area should be elucidated in further in-depth approach.

\section{CONCLUSION}

Cyclops vicinus was dominant during winter, and this is significantly related to withered vegetation area and dissolved oxygen among diverse environmental factors. Therefore, the presence of withered vegetation might be considered as an important factor in determining C. vicinus distribution during winter. The withered vegetation in water body supports tolerance of Cyclops population to unfavorable growth condition (i.e., low temperature in winter), leading to persistence of population size at a certain level. Although copepods prefer high water temperatures for increasing their density and population growth, if Cyclops can overcome low temperature stress that leads to disruption of population, their population growth initiation in the next growing season (i.e., next spring) is possibly propelled by the winter population. Moreover, the 
tolerance to winter season may advantage Cyclops population to avoid extensive predation impact in summer.

\section{ACKNOWLEDGMENTS}

This study was supported in part by the Ministry of Environment (Long Term Ecological Research 2010-2011).

\section{LITERATURE CITED}

Beyst B, Buysse D, Dewicke A, Mees J. 2001. Surf zone hyperbenthos of Belgian sandy beaches: seasonal patterns. Estuar Coast Shelf Sci 53: 877-895.

Brandt SB. 1993. The effect of thermal fronts on fish growth: a bioenergetics evaluation of food and temperature. Estuaries 16: 142-159.

Byström P, Andersson J, Kiessling A, Eriksson LO. 2006. Size and temperature dependent foraging capacities and metabolism: consequences for winter starvation mortality in fish. Oikos 115: 43-52.

Carey MP, Maloney KO, Chipps SR, Wahl DH. 2010. Effects of littoral habitat complexity and sunfish composition on fish production. Ecol Freshw Fish 19: 466-476.

Dejen E, Vijverberg J, Nagelkerke LAJ, Sibbing FA. 2004. Temporal and spatial distribution of microcrustacean zooplankton in relation to turbidity and other environmental factors in a large tropical lake (L. Tana, Ethiopia). Hydrobiologia 513: 39-49.

Escribano R, Hidalgo P. 2000. Spatial distribution of copepods in the North of the Humboldt Current region off Chile during coastal upwelling. J Mar Biol Ass UK. 80: 283-290.

Hirche HJ. 1987. Temperature and plankton. II. Effect on respiration and swimming activity in copepods from the Greenland Sea. Mar biol 94: 347-356.

Hoffmeyer MS. 1994. Seasonal succession of Copepoda in the Bahía Blanca estuary. Hydrobiologia 292/293: 303308.

Huq A, West PA, Small EB, Huq MI, Colwell RR. 1984. Influence of water temperature, salinity, and $\mathrm{pH}$ on survival and growth of toxigenic Vibrio cholerae serovar 01 associated with live copepods in laboratory microcosms. Appl Environ Microbiol 48: 420-424.
Jang MH, Joo GJ, Lucas MC. 2006. Diet of introduced largemouth bass in Korean rivers and potential interactions with native fishes. Ecol Freshw Fish 15: 315-320.

Kuczyńska-Kippen NM, Nagengast B. 2006. The influence of the spatial structure of hydromacrophytes and differentiating habitat on the structure of rotifer and cladoceran communities. Hydrobiologia 559: 203-212.

Manatunge J, Asaeda T, Priyadarshana T. 2000. The influence of structural complexity on fish-zooplankton interactions: a study using artificial submerged macrophytes. Environ Biol Fish 58: 425-438.

Marneffe Y, Descy JP, Thome JP. 1996. The zooplankton of the lower river Meuse, Belgium: Seasonal changes and impact of industrial and municipal discharges. Hydrobiologia 319: 1-13.

Mizuno T, Takahashi E. 1999. An illustrated guide to freshwater zooplankton in Japan. Tokai University press, Tokyo.

Robinson WR, Peters RH, Zimmermann J. 1983. The effects of body size and temperature on metabolic rate of organisms. Can J Zool 61: 281-288.

Roff JC, Middlebrook K, Evans F. 1988. Long-term variability in North Sea zooplankton off Northumberland coast: productivity of small copepods and analysis of trophic interactions. J Mar Biol Assoc UK 68: 143-164.

Sand-Jensen K, Søndergaard M. 1981. Phytoplankton and epiphyte development and their shading effect on submerged macrophytes in lakes of different nutrient status. Int Rev Ges Hydrobiol Hydrogr 66: 529-552.

Ter Braak CJF, Smilauer P. 1998. CANOCO reference manual and user's guide to CANOCO for Windows: Software for canonical community ordination. Version 4. Microcomputer Power, Ithaca, New York, USA.

Theel HJ, Dibble ED. 2008. An experimental simulation of an exotic aquatic macrophyte invasion and its influence on foraging behavior of bluegill. J Freshwater Ecol 23: 7989.

Turner JT. 1984. The feeding ecology of some zooplankters that are important prey items of larval fish. NOAA Technical Report NMFS 7. NOAA, Washington, DC.

Van Donk E, Van de Bund WJ. 2002. Impact of submerged macrophytes including charophytes on phyto- and zooplankton communities: allelopathy versus other mechanisms. Aquat Bot 72: 261-274.

Wetzel RG, Likens GE. 2000. Limnological Analyses. 3rd ed. Springer, New York, pp 20-70. 